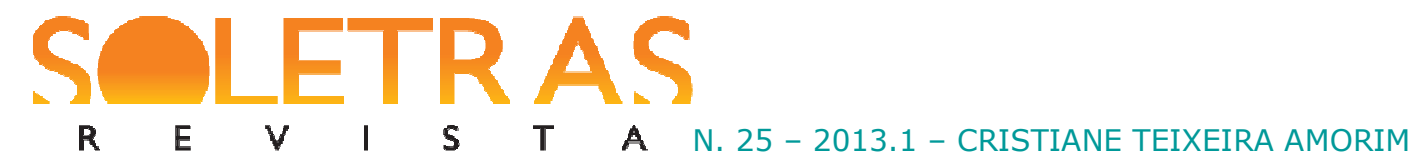

\title{
Sombra severa: a obra secular de Raimundo Carrero
}

\author{
Cristiane Teixeira Amorim ${ }^{1}$
}

\begin{abstract}
Resumo: Em Sombra severa, quarto título carreriano, lançado em 1986, o escritor sertanejo incorpora não apenas cartas à narrativa, caracterizando personagens e dando sentido à ficção, como também faz uso - de modo por vezes invertido - de nomes e circunstâncias dos Testamentos. O irmão de Abel, por exemplo, na trama carreriana, apesar de invejá-lo e matálo como ocorre no Gênesis, se chama Judas, e não Caim. Logo, neste caso, o diálogo se dá não apenas entre a prosa do autor pernambucano e a determinada passagem das Escrituras, mas entre Sombra severa e os trechos relacionados a Caim/Abel e Judas/Cristo. Mesclando os universos cristão e pagão, o ficcionista elabora um jogo textual com contínuos desdobramentos interpretativos. Este trabalho procura, portanto, "desembaralhar" parcialmente a trama pela análise, sobretudo, das inúmeras referências bíblicas que dão corpo ao romance, na intenção última de evidenciar a tese de que o homem (de todos os tempos e lugares) é sempre o mesmo, culpado e inocente, prisioneiro da continuidade cíclica ("correspondência e reintegração") da existência. O texto de Ormindo Pires Filho, "Elementos religiosos em Raimundo Carrero", publicado em 1988, no Diário de Pernambuco, também auxilia nesta análise das relações intertextuais que fazem de Sombra severa prosa secular imersa no sagrado e no profano -, símbolo da repetição ininterrupta das mesmas ações humanas, motivadas pelos mesmos contraditórios sentimentos, através dos séculos.
\end{abstract}

Palavras-chave: Raimundo Carrero. Ficção contemporânea. Prosa brasileira.

[...] o passado retornando é sempre presente: a esfera não tem princípios nem lados, infinita no seu começo e no seu fim [...] (CARRERO, 2008, p.65).

Carlos Nejar, em História da literatura brasileira, após expor os pontos centrais da prosa de Raimundo Carrero, um dos "grandes nomes na ficção surgidos após a década de 70" (2011, p. 900), ao lado de Raduan Nassar, Lya Luft, Caio Fernando Abreu, João Gilberto Noll, Bernardo Carvalho e Silviano Santiago, dentre outros, afirma: “[...] as duas maiores realizações estéticas de Carrero, a nosso ver, são os romances - Sombra severa (1986), tendo capítulos com estampas de cartas e o texto, um jogo de cartas; e As sombrias ruínas da alma (1999) [...]" (NEJAR, 2011, p. 907).

De fato, o autor pernambucano cria um baralho original, uma mescla de referências da cartomancia, da taromancia e da numerologia, utilizado por uma das personagens na tentativa

\footnotetext{
${ }^{1}$ Doutora em literatura brasileira pela UFRJ. Autora de Faces da morte na prosa brasileira e Tamanho G. Organizadora das coleções Era uma vez o bullying e Ecoar (Garamond). Professora substituta do Colégio Pedro II. E-mail: cristiane.amorim@globo.com. 


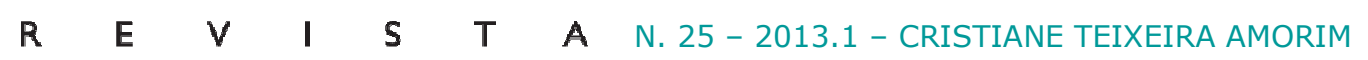

de compreender sua sorte. As cartas, portanto, estão entremeadas: as comuns - compostas pelos naipes ouros, copas, espadas e paus - se misturam a peças ilustradas, próprias de jogos de adivinhação. Este baralho embaralhado se entrelaça à trama textual não apenas abrindo capítulos - conforme salienta Nejar (2011) - e indiciando características dos seres ficcionais e suas ações, mas como parte integrante do próprio texto, conferindo-lhe sentido, sobretudo através das leituras iconográficas realizadas por Judas, o bruxo, e pelo leitor/pesquisador.

Todavia, o entrançamento dos fios que compõem esta narrativa é ainda mais complexo: quase todos os seus integrantes possuem nomes bíblicos e/ou suas histórias têm como base algum episódio do texto sagrado. Esse diálogo intertextual por si só seria capaz de enriquecer a obra, já que a ficção, de certa maneira, se duplica. Carrero, no entanto, consegue acentuar a gama de tons de sua prosa ao inverter antropônimos e circunstâncias dos Testamentos. Assim, por exemplo, o irmão de Abel, na trama carreriana, apesar de invejá-lo e matá-lo como ocorre no Gênesis, se chama Judas, e não Caim. Logo, neste caso, o diálogo se dá não apenas entre a prosa do pernambucano e a determinada passagem das escrituras, mas entre Sombra severa e os trechos relacionados a Caim/Abel e Judas/Cristo. Deve-se ainda atentar que religiosidade e ocultismo (o universo cristão e pagão) também se entrelaçam. Raimundo Carrero, portanto, embaralha o jogo diversas vezes, abastecendo o texto com uma multiplicidade de sentidos assustadora para uma obra de pouco mais de cem páginas.

A presente pesquisa procura, então, "desembaralhar" parcialmente a trama pela dissecação das referências bíblicas que dão corpo ao romance carreriano. A história central de Sombra severa é composta por três personagens principais: os irmãos - Judas, o mais novo, e Abel; e o vértice do triângulo, Dina, filha de Sara e Adão. No primeiro capítulo, Abel rapta a amada e a leva para a fazenda de Jati. Cientes de que logo os Florêncio darão falta da irmã e desejarão vingança, Judas elabora um plano: simular a morte do irmão. Enquanto o pseudodefunto Abel jaz em seu caixão, Judas o trai ao violentar a filha de Sara. Inácio e Jordão, ignorando o estupro e satisfeitos com a morte do responsável pela vergonha da família, exigem apenas o casamento de Judas e Dina, já que ela não mais poderia retornar a casa. O traidor aguarda o duelo com o irmão, mas este, embora irado e ferido, nada faz. Judas mata, então, a punhaladas, Abel.

$\mathrm{Na}$ segunda metade da obra, o assassino expia sua culpa e procura compreender a origem de seu ódio e a razão de seu ato vil. Vem à tona, pela memória, a infância dos meninos em Jati: a suposta preferência que o pai tem pelo filho mais velho; o sorriso, o olhar, a beleza e a destreza do irmão - estímulos à inveja e indicadores da preferência divina; e o dia 


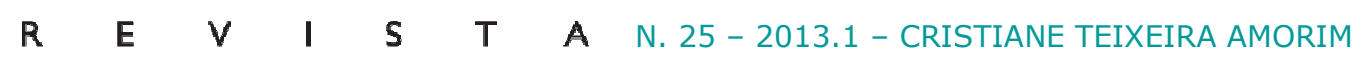

em que o padrinho Teodoro presenteia o afilhado com um carneiro, que tem a garganta cortada e é queimado vivo por Judas na pedra no alto do monte.

A narrativa sugere, no último capítulo, que Judas falece encerrado no quarto. São estes os elementos indiciadores: a visão dos anjos guerreiros, "cada um com uma espada flamejante na mão" (CARRERO, 2008, p. 125), possíveis anunciadores da morte e da penitência; a substituição no texto do pretérito perfeito pelo perfeito do verbo poder ("Judas não pôde pode - nunca revelar se foi um sonho [...])" (CARRERO, 2008, p. 125) e a presença das duas cruzes nas cartas, prováveis símbolos do óbito de ambos os irmãos. Ormindo Pires Filho (1988) corrobora o ponto de vista ao afirmar que "o próprio desespero de Judas, seu próprio lento e inexorável suicídio por inanição pode ser um sinal de arrependimento e de penitência [...]" (PIRES FILHO, 1988, p. B-6).

E quem são Caim (e Judas), Abel e Dina nos textos sagrados? Caim é lavrador e irmão mais velho de Abel, pastor de ovelhas. Para presentear o Senhor, o primeiro oferece um fruto da terra e o segundo as "primícias de seu rebanho" (Genesis 4, 4). Mas Deus aprecia a oferta do filho mais novo de Adão e desgosta do regalo de Caim. Este, tomado pela inveja, mata o irmão. O Senhor condena, assim, o primeiro homicida a ser errante pela terra. $\mathrm{O}$ assassino lamenta sua punição: “[...] É tamanho o meu castigo, que já não posso suportá-lo” (Gênesis 4,13) e teme a sua morte: "[...] quem comigo se encontrar me matará” (Gênesis 4,14), mas não há nenhum sinal de seu remorso. Já o Judas (Caim) de Carrero é corroído pela culpa. O peso na alma atinge o corpo insone e derrotado: “O corpo já doía. Para todos os lados que se movimentasse, as dores voltavam. Já não era mais apenas o arrependimento. Aparecia-lhe a dor física. Insuportável. Tonteiras, náuseas, cansaço” (CARRERO, 2008, p. 123).

Todavia, no evangelho de Mateus, encontra-se o infiel compungido que, como a personagem carreriana, escolhe para si a morte: "Pequei, traindo sangue inocente. [...]" / "Então Judas, atirando para o santuário as moedas de prata, retirou-se e foi enforcar-se" (Mateus, 27, 4.5). Carrero, com a substituição dos nomes, consegue manter o diálogo com o antropônimo escolhido e o aparentemente renegado e nutrir a narrativa com as referências de ambos.

Agora, o que há de comum entre Caim e Judas? Ambos são traidores; ambos tiveram, talvez, a inveja como motor de suas ações; ambos se tornaram homicidas pois, embora o apóstolo não tenha matado Cristo com as próprias mãos, foi metaforicamente seu assassino; e, principalmente, ambos se rebelaram contra o poder divino. No entanto, na Bíblia Católica oficial, nem Caim nem Judas explicitam as razões que os levaram ao crime. Carrero parece, 
$\begin{array}{llllllll}\mathbf{R} & \mathbf{E} & \boldsymbol{V} & \mathbf{I} & \mathbf{S} & \mathbf{T} & \mathbf{A} & \mathrm{N} .25-2013.1 \text { - CRISTIANE TEIXEIRA AMORIM }\end{array}$

no remoer incessante de sua personagem torturada, levantar não apenas os supostos agentes motivadores do assassinato de Abel por Judas, mas (e, talvez, sobretudo) questionar implicitamente as causas das ações do filho de Adão e do apóstolo de Cristo. A pergunta "de quem é de fato a culpa?” subjaz na ficção carreriana, ao mesmo tempo em que, na inquirição constante de Judas sobre a origem de sua inveja e de seu ódio, "segredo dos antepassados" (CARRERO, 2008, p. 64), se encontra também subentendida a indagação: "É possível escapar ao destino de ser humano?".

Uma interpretação plausível das escrituras se fundamenta na ideia de que Caim não matou Abel por ciúmes, ou ao menos não somente por este sentimento, mas por desejar punir Deus. Ele se revolta:

[...] por todos aqueles que não aceitam esse mistério de predestinação, que divide o homem em rejeitados e eleitos, todos aqueles que não compreendem o desprezo de Deus pelas grandezas terrenas e sua predileção pelos humildes. É contra essa ordem de Deus que ele se revolta quando abre com uma pedra afiada a garganta de Abel, o favorito do céu (CHEVALIER; GHEERBRANT, 2005, p. 162-1633).

Sob essa perspectiva, pode-se afirmar que, se Deus pune o homem com a finitude ("tu és pó e ao pó retornarás" (Gênesis, 3,19) - diz a Adão), Caim, o primeiro homicida, mata Abel para punir Deus. Com o crime, o mundo conhece a morte, a amargura do "último fruto da árvore da sabedoria". Do mesmo modo, o Judas carreriano compreende, ao iniciar sua reveladora descida aos meandros da infância, que "desvendar os mistérios já era o começo do castigo. Há pessoas que nascem para ser castigadas" (CARRERO, 2008, p. 65). Depreendese, portanto, dessas sentenças, três proposições intrínsecas: conhecer é sofrer; há um Destino do qual não se pode fugir e, se não é possível fugir do Destino (não existe livre-arbítrio), o culpado é, de certo modo, inocente. O Ato dos Apóstolos parece corroborar a tese de que o traidor não teve escolha: "Convinha que se cumprisse a Escritura que o Espírito Santo proferiu anteriormente por boca de Davi, acerca de Judas, que foi o guia daqueles que prenderam Jesus" (Atos, 1,16).

Numa obstinada e agônica tentativa de desvendar as razões dos crimes, estupro e assassinato, (e do ódio pelo irmão), e também de eximir-se da culpa, Judas responsabiliza:

1. Os pais e, sobretudo, o pai (possível metáfora para o Criador): “Abel [...] sempre recebia os melhores cuidados" (CARRERO, 2008, p. 65); "O pai, tão casmurro, brincava com o filho [Abel], o que não reservava para Judas" (CARRERO, 2008, p. 


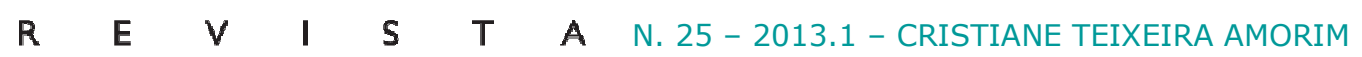

65). Deve-se destacar que, embora a fala seja do narrador heterodiegético, o ponto de vista é de Judas.

2. Abel, por sua beleza e vivacidade, e por ter trazido Dina a casa, ciente de seu amor por ela: "Foi o sorriso de Abel [...]" (CARRERO, 2008, p. 67); “[...] o sorriso ou o olhar?" (CARRERO, 2008, p. 68); "A culpa fora de Abel, ele que trouxera Dina, que sabia, sabia, gostava dela bem de longe" (CARRERO, 2008, p. 43).

3. Dina, por tê-lo enfeitiçado: "Mas as mulheres, como aquela, têm feitiço. Fosse outra, talvez nem tivesse olhos para vê-la" (CARRERO, 2008, p. 43).

4. O Destino, por exterminar a escolha: “[...] estava certo de que as ações não nasciam de sua alma atormentada, mas das emboscadas que o segredo sabe preparar" (CARRERO, 2008, p. 45); “[...] o mundo arrebentara as portas para o homem com o Pecado" (CARRERO, 2008, p. 68). A recorrente imagem da serpente - em clara referência ao episódio da queda - como causadora de seus infortúnios, também de certa maneira surge como atenuante de responsabilidade: "a serpente enrodilhada no coração, esperando a hora maldita do bote” (CARRERO, 2008, p. 68). Há algo ainda de eterno retorno do qual não se pode escapar na indagação: "Matar um irmão não era como matar todos os irmãos juntos?” (CARRERO, 2008, p. 117).

5. Deus, por tê-lo abandonado e por preferir Abel:

O homem conhece Deus, e embora $\mathrm{O}$ conheça e $\mathrm{O}$ venere, não consegue escapar do visgo atraente do inferno. E quando Deus o abandona, às vezes por um instante, às vezes por descuido, ou cansado pela renitência do Pecado, não pode escapar ao castigo. Seria castigo, castigo mesmo? Merecia? Deus o esquecera por um instante, quem sabe cuidando de Abel, e agora impunha o sofrimento. Não merecia. Era o que não merecia, porque não tinha culpa dos descuidos do Senhor (CARRERO, 2008, p. 64).

Ormindo Pires Filho (1988, p. B-6) afirma que, de certo modo, o livro de Carrero é “querigmático". No entanto, e embora o próprio autor pernambucano não se canse de reafirmar sua religiosidade, a rebeldia de suas personagens (ainda que quase sempre punidas), parece sempre despertar a simpatia do leitor porque este conhece a fundo os tormentos de suas almas e as razões de seus crimes, suas dores e suas terríveis penitências. Carrero não alerta: cumpram as escrituras para que não sejam castigados. Ao contrário, o ficcionista reconhece a angústia de viver sobre o tênue fio que separa bem e mal; o sofrimento pela incapacidade de o indivíduo ser plenamente bom. A condição humana, múltipla e contraditória, é o Destino do 
qual não se pode apartar. Em entrevista, sobre a questão do pecado em Sombra severa, Carrero responde que seu romance

[...] é uma metáfora da transgressão humana. E uma metáfora ainda maior do escritor, do criador enfim, que se rebela contra o mundo e, no entanto, é seu melhor amigo. Ou seja, Judas estupra a noiva do irmão, Abel, mata-o em seguida e é capaz de sofrer por ele, porque só ele é capaz de amá-lo (PEREIRA, 2009, p. 82).

Já Carlos Nejar (2011, p. 907) defende que o reino de Carrero é

[...] o sertão, que tende sempre ao dramático e punitivo, sob os grilhões de inarredável culpa. Pessimista ao niilismo, é rude e até agressivo, como se a felicidade fosse amargura. [...] É um criador de personagens que se entretecem nos extremos, seja do amor, seja do desespero.

Outro elemento presente tanto na narrativa bíblica quanto na carreriana é o carneiro. Enquanto, no Genesis, Abel presenteia o Senhor com "as primícias de seu rebanho", na ficção, é Teodoro, "do grego Theo-doros, dom, dádiva de Deus" (Obata, 2002, p.183), que carrega no nome a imagem "daquele que adora" ou é adorado, quem presenteia Abel com o animal - chamado de Jasmim pela mãe dos meninos, provavelmente pela cor das flores desta espécie, em geral, brancas como a lã. Logo, na Bíblia, Abel dá o presente a Deus e, em Sombra severa, Abel recebe o presente (dom, dádiva) de Deus, o que se verifica através do antropônimo Teodoro. Judas o odeia porque ele é metaforicamente a encarnação da preferência divina por seu irmão. Em outro instante narrativo, no entanto, Judas parece lamentar que Teodoro seja padrinho de Abel e não seu, ou seja, que a "dádiva" não lhe pertença: "Na verdade, para ser sincero, às vezes admirava o padrinho Teodoro. O porte de beleza. Não lembra que sozinho, imitando o riso, dizia: padrinho Teodoro?” (CARRERO, 2008, p. 70).

E se, no texto sagrado, Caim - ferido em sua vaidade pelo Senhor não ter se agraciado com sua oferenda - corta a garganta do irmão, na prosa carreriana, Judas, invejando Abel por ter recebido o presente, sacrifica o carneiro, na pedra sobre o monte, também com um talho no pescoço e o queima vivo. Sobrepondo as duas narrativas, é possível verificar que o animal é simbolicamente o manso Abel, a quem Judas, portanto, deseja matar desde a infância. Essa passagem parece dialogar ainda com a subida do monte por Moisés para escrever os mandamentos na tábua de pedra. Nesse instante, “o aspecto da glória do Senhor era como um 
$\begin{array}{lllllllll}\mathbf{R} & \mathbf{E} & \mathbf{V} & \mathbf{I} & \mathbf{S} & \mathbf{T} & \mathbf{A} & \mathrm{N} .25-2013.1 \text { - CRISTIANE TEIXEIRA AMORIM }\end{array}$

fogo consumidor no cimo do monte, aos olhos dos filhos de Israel" (Êxodo 24, 17). Quando o menino Judas chega a casa, perguntam-lhe se ele "vira o fogo" (CARRERO, 2008, p. 76). No monte bíblico, animais foram servidos em holocausto, prática comum à época e, em Exôdos, por exemplo, o Senhor ordena o derramamento de sangue de animais e, como sacrifício pelo pecado, que sejam queimadas as carnes do novilho sobre o altar. Gaarder, Hellern e Notaker, em O livro das religiões (2011, p. 31), quanto aos sacrifícios de expiação, afirmam que, na maioria das crenças religiosas,

[...] se um indivíduo cometeu um crime contra os deuses e despertou sua ira, deve ser punido. Para apaziguar os deuses e evitar uma vingança, ele pode fazer um sacrifício de expiação. A oferenda - por exemplo, um animal sacrificial - substitui o culpado e é punida no lugar dele.

Mas qual o significado desses entrelaçamentos? Assim como o tio Lourenço, em As sementes do sol (1981), profana os rituais sagrados, Judas macula, neste ato mimético, as passagens bíblicas com as quais o texto dialoga. O holocausto era um pedido de perdão; em Sombra severa, ele é o próprio pecado: não é presente, oferenda, mas afronta. Do mesmo modo que Caim afrontou Deus matando Abel.

O irmão de Judas, aliás, morre e ressuscita inúmeras vezes: na infância é metaforicamente assassinado com um golpe na garganta e queimado vivo (quem morre na verdade é o carneiro); após raptar a amada, simula a própria morte (caíra de um cavalo, diz Judas aos irmãos Florêncio) e percebe o risco de seu ato: "Fingir a morte não é atraí-la?" (CARRERO, 2008, p. 24); depois da ressurreição do reino do fingimento, morre de fato, ratificando o presságio, com dois golpes no peito e, então, renasce em Dina: lenta gestação que se completa ao final da narrativa quando ela se veste com as roupas brancas de Abel, corta os cabelos e monta o cavalo branco.

A história que corre em paralelo (e, obviamente, entrelaçada à principal) refere-se a Sara e Adão, pais de Dina. Ambos também fugiram para ficar juntos e os irmãos da mulher (assim como os Florêncio, "filhos da fuga" (CARRERO, 2008, p. 84), vão atrás de Dina anos mais tarde) os perseguem. Eles se refugiam numa hospedaria e, para despistar, ocupam quartos separados e se dizem parentes. Quando os rapazes perguntam pelo casal ao dono do estabelecimento, este afirma que só irmãos ocupam o local. Após saberem a verdade, crêem que o proprietário mentira e, então, o matam. 
$\begin{array}{llllllll}\mathbf{R} & \mathbf{E} & \boldsymbol{V} & \mathbf{I} & \mathbf{S} & \mathbf{T} & \mathbf{A} & \mathrm{N} .25-2013.1 \text { - CRISTIANE TEIXEIRA AMORIM }\end{array}$

Surpreendentemente, há neste episódio vários entrecruzamentos com os textos sagrados. Diná (Dina) surge no Genesis; é filha de Jacó e Lia, violentada por Siquém, que por ela posteriormente se apaixona e com ela deseja se casar. Apesar de os irmãos de Diná, Simeão e Levi, terem aparentemente concordado com a união, matam o estuprador e seu pai. $\mathrm{Na}$ narrativa carrerina, Dina (Diná) também é violada, mas por Judas. Este, embora a rejeite após o ato e demonstre nojo pela amada de Abel, afirma em aparente contradição emparelhando-se com Sequém: "Agora, porém, que o desejo se transformava em paixão, perdia a força" (CARRERO, 2008, p. 110). No entanto, os irmãos Inácio e Jordão, em Sombra severa, sequer tomam ciência do ato criminoso de Judas.

Outro ponto de toque: Sara e Adão só conseguiram gerar filhos quando bem velhos (do mesmo modo que a Sara e o Abraão bíblicos), após a visita de três ciganos. A diferença é que as personagens do Gênesis recebem dois anjos e o Senhor (e não ciganos), anunciadores da futura gestação. Novamente, na prosa de Carrero, a sacralidade é substituída pelo ocultismo. Ambas as Saras, ouvindo a conversa escondidas, riem da "profecia", por não acreditarem mais em sua capacidade de procriar, e são criticadas. Há ainda a referência à velhice dos pais de Dina durante sua cerimônia de casamento em diálogo com o fato de que o casal bíblico vive por mais de um século. E as alusões não findam: no Antigo Testamento, Abraão se diz irmão de Sara para evitar que homens embevecidos com a beleza da mulher o matem; já na prosa do pernambucano, como já apontado, o casal também utiliza o mesmo artifício, mas para despistar os perseguidores. No texto sagrado, Abimeleque quase morre por conta da mentira, ameaçado pelo Senhor por tentar coabitar com a esposa de Abraão e, em Sombra severa, o dono da hospedaria é realmente assassinado. Aliás, deve-se notar que, na Bíblia, Sara e seu esposo em verdade não mentem, pois de fato são meio irmãos. Eles, portanto, apenas omitem que se uniram em matrimônio.

Carrero elabora uma narrativa na qual, sobretudo pela intertextualidade, as personagens se duplicam, formando dicotomias bastante significativas: Dina é (e não é) Diná; Judas é e não é Caim, Adão é (e não é) Abraão, Abel é (e não é) o carneiro sacrificado e é (e não é) Cristo, o Cordeiro de Deus oferecido em holocausto; Jordão e Ismael são (e não são) Simeão e Levi. Pode-se ainda dizer que Dina é (e não é) Sara, se for considerado o destino que se repete, promovendo uma fusão de personas.

Todavia, qual o principal efeito de sentido dessa intertextualidade? A ideia-base se encontra evidenciada já na epígrafe principal, retirada da obra José e seus irmãos, de Thomas 
Mann. No trecho abaixo é possível verificar a concepção de uma espécie de eterna correspondência gerada por um movimento cíclico e contínuo:

\begin{abstract}
E aqui, na verdade, nossa narração vem desembocar em mistérios e nossos pontos de referência se perdem no sem-fim do passado, onde toda origem se trai, revelando ser apenas uma parada aparente e uma meta inexpressiva, misteriosa por sua própria natureza, uma vez que esta não se assemelha a uma linha, mas a uma esfera. Mas a esfera consiste em correspondência e reintegração [...] (apud CARRERO, 2001, p. 11).
\end{abstract}

Pode-se encontrar no texto carreriano a mesma tese: “[...] o passado retornando é sempre presente: a esfera não tem princípios nem lados, infinita no seu começo e no seu fim [...]" (CARRERO, 2008, p. 65). Nas inúmeras vezes em que Judas se pergunta "Onde estaria o começo?" (CARRERO, 2008, p. 64), a busca não recua apenas até sua infância, mas, simbolicamente, pelo entrecruzamento com o texto sagrado, ao começo de toda a história humana, assim como a afirmação de Dina, "A fuga vinha do sangue" (CARRERO, 2008, p. 20) - embora faça referência ao fato de a mãe (Sara) também ter abandonado o lar - retrocede dialogicamente ao Exxodo, com a fuga de Sarai e Abraão (e de todo um povo) para a terra prometida.

Permanece a pergunta: mas o que se repete? Os atos abomináveis movidos pelas paixões da alma e a atormentadora culpa deles decorrente que com frequência leva à loucura ou à morte. Não importa o passar ininterrupto e veloz dos tempos, porque a linha não é reta caracterizando uma escala evolutiva. O homem para Carrero, é sempre o mesmo (o que provavelmente justifica o fato de a "localização" temporal das narrativas do autor pernambucano ser arcaizante): contraditório, múltiplo e - por que não afirmar? - pecador, transgressor incorrigível. Nas narrativas analisadas até então encontram-se três fratricídios: Anrique mata Pedro Militão, em A história de Bernarda Soledade (1975); Absalão mata Agamenon, em As sementes do sol (1981); e Judas mata Abel Sombra severa (2008). Já em A dupla face do baralho (1984), Félix Gurgel encomenda a morte do próprio pai. Todos os assassinatos ocorrem no seio da família, sinédoque da sociedade. E Carrero, nesse leitmotiv, também reafirma a crença na continuidade cíclica ("correspondência e reintegração") da existência. Ainda: em todos os títulos - com exceção de Bernarda Soledade - verifica-se que o comportamento dos seres de algum modo se justifica por fatos transcorridos na infância, possível metáfora de tempos imemoriais. 
Separar o bem do mal na obra do prosaísta sertanejo pareceu fácil a vários críticos, porém a dor de algumas das suas criminosas personagens, por não terem evitado o crime, e o flagelo psicológico a que se submetem revelam a plenitude de sua dual humanidade. $\mathrm{O}$ irmão de Abel o mata não simplesmente pelo ódio, mas (e, talvez, sobretudo) porque "o amor é a inveja do outro [...]" (CARRERO, 2008, p. 66). Os sentimentos na ficção carreriana são menos estruturalmente puros do que o senso comum costumeiramente os supõem, do mesmo modo que bem e mal não são pólos opostos; ao contrário, eles estão emaranhados, embaralhados. A compaixão por Judas, “o castigado" (CARRERO, 2008, p. 65), é acentuada ainda pela sentença "O mistério é que nem ele sabia que se transformaria depois num criminoso" (CARRERO, 2008, p. 119).

Raimundo Carrero edifica uma prosa secular - profana e imersa no sagrado - símbolo da repetição ininterrupta das mesmas ações humanas, motivadas pelos mesmos sentimentos, através dos séculos.

\section{Referências bibliográficas:}

BÍBLIA SAGRADA. Português. Tradução ecumênica. Baseada na tradução do Padre Antonio Pereira de Figueiredo. São Paulo: O.E.S.P; Maltese, 1962.

CARRERO, Raimundo. Sombra severa. São Paulo: Iluminuras, 2008.

CHEVALIER, Jean; GHEERBRANT, Alain. Dicionário de símbolos. Rio de Janeiro: José Olympio, 2005.

NEJAR, Carlos. História da literatura brasileira: da carta de Caminha aos contemporâneos. São Paulo: Leya, 2011.

GAARDER, Jostein; HELLERN, Victor; NOTAKER, Henry. O livro das religiões. São Paulo: Companhia das Letras, 2005.

OBATA, Regina. O livro dos nomes. São Paulo: Nobel, 2002.

PEREIRA, Marcelo. Raimundo Carrero: a fragmentação do humano. Recife: Caleidoscópio, 2009.

PIRES FILHO, Ormindo. Elementos religiosos em Raimundo Carrero, Diário de Pernambuco, Recife, 5 ago. 1988, Caderno Viver, p. B-6. 


\section{Sombra severa: the secular work of Raimundo Carrero}

Abstract: In Sombra severa, the fourth book of Carrero, issued in 1986, the sertanejo writer incorporates to the romance not only letters, typifying the character and giving a meaning to the fiction, as well as he uses the names and circumstances of the Testament (many times twisted). Abel's brother, for example, in the carreriana story, although he envies and kills him as in the Genesis, his name is Judas and not Cain. Thus, in this case, the dialogue happens not only between the prose of the author from Pernambuco and certain pieces of the Bible, but also between Sombra severa and the pieces related to Cain/Abel and Judas/Christ. Mixing the christian and pagan universes, the novelists draws a textual game with continuous interpretative possibilities. This work proposes, therefore, to partially unshuffle the story by the analysis of innumerous bible citations which give body to the romance, in the utmost intention of evidencing the thesis that the man (from any time and place) is always the same, guilty or innocent, a prisoner of the cyclic continuity of the existence ("corresponding and reintegrating"). The text of Ormindo Pires Filho, "Religious elements in Raimundo Carrero", published in 1988, in the Diário de Pernambuco, also reinforces this analysis of the inter-textual relations which makes Sombra severa a secular prose - immerse in the sacred and profane -, symbol of the never ending repetition of the same human actions, motivated by the same contradictory feelings along the centuries.

Key words: Raimundo Carrero. Contemporary fiction. Brazilian prose.

Artigo recebido em: 30 de maio de 2013.

Artigo aprovado em: 17 de junho de 2013. 